\title{
Smoking and Blindness
}

\section{What Optometrists Want their Patients to See}

\section{BY MARLEE M. SPAFFORD, OD, PhD; RYAN D. KENNEDY, MAES, PhD; MATTHEW D. ILEY, BSC, OD;}

ANNETTE S.H. SCHULTZ, RN, PhD

\begin{abstract}
Most smokers are not aware that their tobacco use is a preventable cause of blindness. Despite the important role optometrists can have impacting patient health choices; their voice has been largely silent in the development of tobacco cessation practice guidelines and health promotion strategies. In this study, we use the International Tobacco Control Policy Evaluation Project (ITC) Four Country Survey to describe the level of Canadian smokers'knowledge of the association of smoking with blindness and we use focus groups to elicit ideas from Canadian optometrists and senior optometry students about blindness-related graphic warning labels.
\end{abstract}

Keywords: Smoking, blindness, graphic warning labels, optometry practice

\section{Introduction}

TV hile tobacco use is widely

known as a preventable cause of premature death, its causal association to blindness is relatively unknown by smokers. There is strong evidence that healthcare providers can positively affect tobacco cessation among their patients yet the voice of optometrists has been largely silent in the development of tobacco cessation practice guidelines and health promotion strategies such as social marketing campaigns and graphic warning labels. Our research group has begun to examine Canadian optometrists' key behaviors and attitudes toward patients who use tobacco. In this paper, we describe the level of Canadian smokers' knowledge of the association of smoking with blindness and the ideas that Canadian optometrists and senior optometry students have about blindness-related graphic warning labels.

\section{Tobacco Use \& Health Impacts}

Optometrists routinely encounter patients who have, do, or will smoke cigarettes. A 2008 report $^{1}$ by the Propel Centre for Population Health Impact provides a compelling average profile of smoking among Canadians. An estimated $17.9 \%$ of Canadians over 14 years of age smoked cigarettes ${ }^{1}$, with higher rates among males (20\%) than females (16\%). Among daily smokers, who were the majority (75.4\%), almost 15 cigarettes were smoked daily. Provincial rates of smoking varied from a low of
14.7\% in British Columbia to a high of $20.8 \%$ in Manitoba with only two provinces having rates below the national average (Ontario and British Columbia). The highest smoking prevalence $(27 \%)$ existed among 20 to 24-year-olds and almost $19 \%$ of students in grades 5 to 9 had tried smoking. According to this report, two-thirds of smokers were seriously considering quitting in the next 6-months.

The leading causes of premature death causally linked to smoking are coronary artery disease, leading to myocardial infarctions and cerebrovascular accidents, lung cancer, and chronic obstructive pulmonary disease. ${ }^{2}$ Public awareness of the negative consequences of smoking is generally high for these diseases; for example, studies in Canada, the United States, the United Kingdom, Australia and Singapore have reported that most surveyed respondents knew that smoking causes lung cancer $(>90 \%)$, heart disease $(>83 \%)$ and stroke $(>70 \%)^{3,4,5}$

Public knowledge that smoking causes sight threatening eye disease is generally much lower, typically less than $10 \% .{ }^{3,6,7}$ Only one study ${ }^{4}$, which focused on eye care seeking smokers, found higher knowledge 
levels between 31 and 37\%. This limited awareness is a significant problem because smoking has been shown to cause several eye diseases through ischemic and oxidative mechanisms. ${ }^{8}$ Smoking has been causally associated with age related macular degeneration ${ }^{9-13}$, nuclear and posterior subcapsular cataract $^{14-19}$, thyroid-associated ophthalmopathy ${ }^{20-22}$, optic neuropathies ${ }^{23-25}$ and uveitis. ${ }^{26,27}$ While public knowledge of smoking-induced eye disease is relatively low, fear of blindness is not. A study ${ }^{6}$ of British youth (16-18 years old) found that, in comparison with lung cancer, heart disease and stroke, blindness was the least known but most feared consequence of smoking cigarettes. Interestingly, some healthcare practitioners (e.g., pharmacists) are finding that linking smoking to blindness has been a successful part of their tobacco cessation advice. ${ }^{28}$

The common occurrence of smoking, the limited public knowledge of smoking-associated eye disease, and the public's fear of vision loss all provide important incentives for optometrists to engage in patient education regarding tobacco prevention and cessation.

\section{Health Practitioners Support- ing Tobacco Prevention \& Cessation}

Addressing tobacco use in clinical practice is supported by an increasing recognition that tobacco use and dependence is a preventable cause of morbidity and mortality and healthcare providers can be effective facilitators of tobacco cessation among their patients. ${ }^{29-34}$
The U.S. Surgeon General's web-site provides clinical practice guidelines, entitled, Treating Tobacco Use and Dependence: 2008 Update. $^{35}$ This document was developed by stakeholders including those from medicine, nursing, dentistry, pharmacy, epidemiology, public health, and psychology. Unfortunately, optometry is notably missing as a stakeholder informant or as an identified user of the document. Optometry has also yet to be a stakeholder in the development of Health Canada's graphic warning labels for tobacco products. Graphic warning labels can be a useful tobacco prevention and cessation strategy, either on cigarette packages or posters. For example, they have been shown to increase the intentions of smokers to quit because of their heightened knowledge of the health effects of smoking. ${ }^{36}$ Health Canada has had the same graphic warning labels on tobacco products for about ten years but it has not yet adopted an eye disease related warning label for smoking despite having one under consideration since 2006 (see the Tobacco Labeling Resource Centre for current and test Canadian warning labels: www. tobaccolabels.ca). In contrast, other countries $^{37-38}$ have already adopted eye-related messages in their tobacco campaigns.

In this paper, we describe Canadian smokers' knowledge of the link between tobacco use and blindness as well as the recommendations of Canadian optometrists and senior optometry students about warning graphic labels specific to eye disease.

\section{Methods}

\section{Canadian Smokers' Knowledge} of Smoking Causing Blindness

Subsequent to institutional ethics clearance, we accessed data on Canadian smokers' knowledge about the health impacts of smoking using the International Tobacco Control Policy Evaluation Project (ITC) Four Country Survey. It is a longitudinal cohort study conducted approximately annually with adult smokers in Canada, the United States, the United Kingdom, and Australia. For the purposes of this study, we focused on the Canadian data. The ITC Four Country survey began in 2002 and has included a measure of respondents' knowledge of smoking and blindness since the third survey in 2004 (called Wave 3). Eligibility for the ITC Canada sample required participants to live in Canada, be at least 18-years-old, have smoked more than 100 cigarettes in their life and at least once in the previous 30 days, and be willing to complete the ITC Four Country phone survey. Further details about the ITC Four Country survey and methods have been published elsewhere. ${ }^{39-41}$ This evaluation method has been found to provide a reliable indicator of national smoking behavior trends. The ITC-4 survey question pertaining to smoking and blindness was worded, I am going to read you a list of health effects and diseases that may or may not be caused by smoking cigarettes. Based on what you know or believe, does smoking cause blindness? 
TABLE 1

Graphic Warning Label Features Discussed

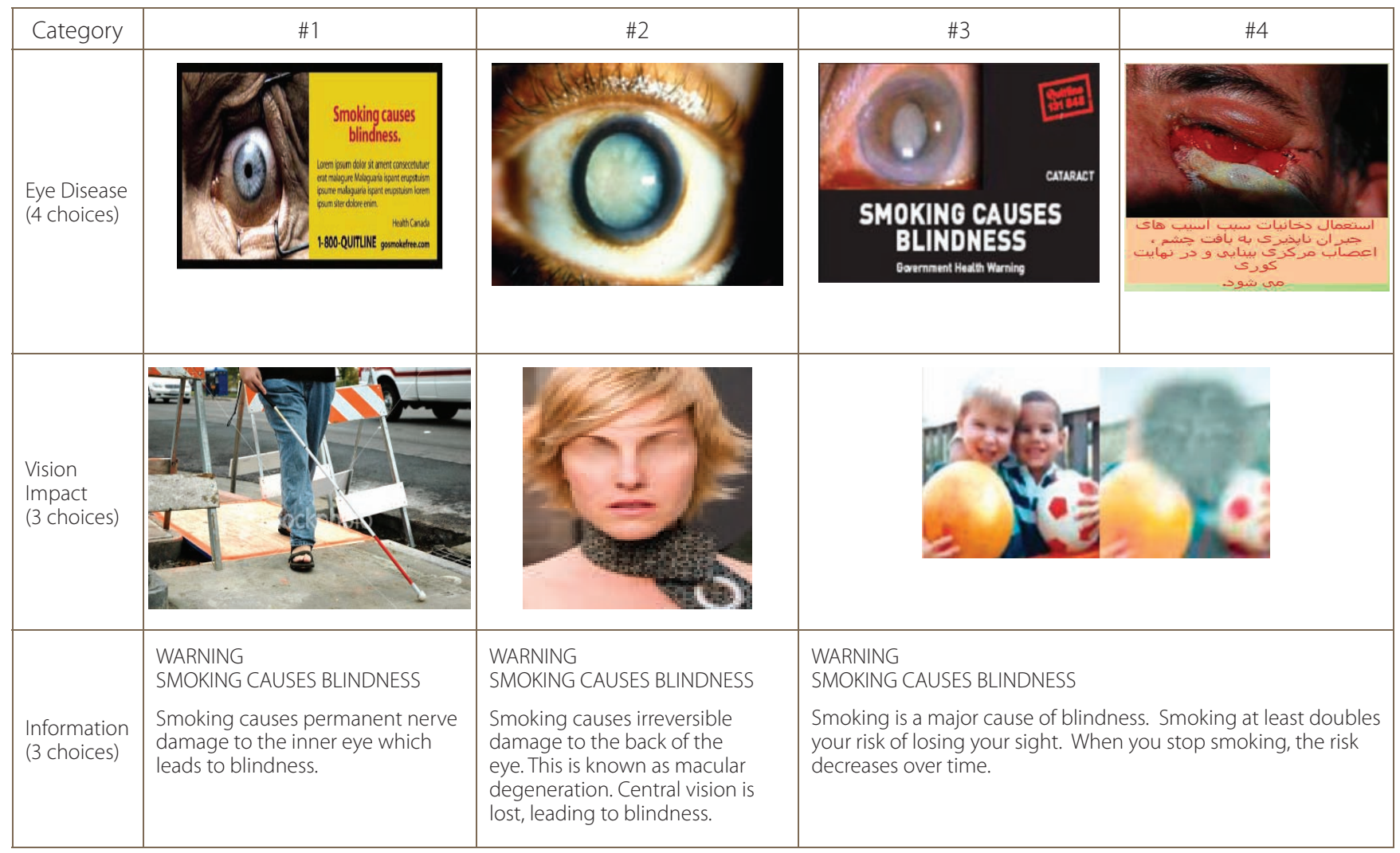

The response options were: 'Yes', 'No', or 'Don't know'. The analysis in this paper is limited to respondents answering the blindness knowledge question for their first time. Since each wave (i.e., year) incorporates new participants to replenish those who have been lost to follow-up, there are new participants in each wave. Combining respondents from waves 3 to 7 (i.e., 2004 to 2008), provided a total weighted sample of 3,839 Canadian daily smokers. Response data were calculated provincially (by count and percentage of respondents); proportions were compared using 2-tailed $z$-tests with an alpha of 0.05 used for significance testing.

\section{Perceptions of Eye-Related Graphic Warning Labels}

Focus groups were conducted with optometry students and community optometrists. The study occurred in the Waterloo Region of southwestern Ontario, Canada in the summer of 2009.

Detailed descriptions of recruitment and sampling for this study have been published previously. ${ }^{42,43}$ The potential participant pool included 51 practicing optometrists and 30 fourth-year optometry students (60 additional fourth-year students were away on external clinical placements). Eighteen fourth-year optometry students (15 women, 3 men) were scheduled into three focus groups (S1, S2, and S3) and eleven optometrists (7 women, 4 men) were scheduled into two focus groups (O1 and O2). These optometrists had been practicing for approximately 20 years, on average, with an individual range from 5 to over 30 years. All but one had graduated from the local Doctor of Optometry program. The 29 participant identities were represented by numbers; for example, the seven members of student focus group S1 were numbered S1-1 to S1-7, and the six members of optometrist group O1 were numbered O1-1 to O1-6.

The multi-disciplinary research team, which drew from optometry, nursing, and psychology, developed a two-phase interview. The first 
TABLE 2

Smokers' Knowledge that Smoking Causes Blindness by Canadian Province

\begin{tabular}{|c|c|c|c|c|c|c|c|c|c|c|c|c|c|}
\hline \multicolumn{3}{|c|}{ PROVINCES } & $\mathrm{NL}$ & PE & NS & NB & QC & ON & $\mathrm{MB}$ & SK & $A B$ & $B C$ & Total \\
\hline \multirow[t]{2}{*}{ Blindness } & \multirow[t]{2}{*}{ Yes } & Count & 10 & 1 & 16 & 15 & 213 & 162 & 18 & 21 & 32 & 55 & 543 \\
\hline & & $\%$ & $14.7 \%$ & $5.3 \%$ & $12.9 \%$ & $14.3 \%$ & $20.5 \%$ & $11.5 \%$ & $13.6 \%$ & $16.4 \%$ & $8.3 \%$ & $13.2 \%$ & $14.2 \%$ \\
\hline & \multirow[t]{2}{*}{ No } & Count & 48 & 16 & 87 & 69 & 681 & 1,016 & 94 & 82 & 294 & 279 & 2,666 \\
\hline & & $\%$ & $70.6 \%$ & $84.2 \%$ & $70.2 \%$ & $65.7 \%$ & $65.7 \%$ & $71.9 \%$ & $71.2 \%$ & $64.1 \%$ & $76.0 \%$ & $67.1 \%$ & $69.6 \%$ \\
\hline & \multirow[t]{2}{*}{$\begin{array}{l}\text { Don't } \\
\text { Know }\end{array}$} & Count & 10 & 2 & 21 & 21 & 143 & 236 & 20 & 25 & 61 & 82 & 621 \\
\hline & & $\%$ & $14.7 \%$ & $10.5 \%$ & $16.9 \%$ & $20.0 \%$ & $13.8 \%$ & $16.7 \%$ & $15.2 \%$ & $19.5 \%$ & $15.8 \%$ & $19.7 \%$ & $16.2 \%$ \\
\hline \multirow[t]{2}{*}{ Total } & & Count & 68 & 19 & 124 & 105 & 1,037 & 1,414 & 132 & 128 & 387 & 416 & 3,830 \\
\hline & & $\%$ & $100 \%$ & $100 \%$ & $100 \%$ & $100 \%$ & $100 \%$ & $100 \%$ & $100 \%$ & $100 \%$ & $100 \%$ & $100 \%$ & $100 \%$ \\
\hline
\end{tabular}

phase addressed attitudes, practices and training regarding smoking behavior and smoking cessation referrals in optometric practice. The second phase focused on collecting reactions about the design content for possible tobacco product warning labels that included messages about tobacco use and eye health. Focus group respondents were given colour print-outs of ten different graphic warning label features designed for the current study by the research team. Some designs used images from graphic warning labels already used in Australia, New Zealand, and Iran. The ten warning labels addressed three categories: 1) 'Eye Disease' (four designs intended to communicate eye disease), 2) 'Vision Impact' (three designs aimed to communicate the experience of vision loss), and 3) 'Text Information' (three designs showed different text messages). The labels were designed to encourage discussion about what features or approaches the respondents felt were important. Table 1 shows the ten graphic label features discussed by the informants. Focus group facilitators (RDK \& KM) were experienced in tobacco control research. A research assistant (VZ) made field notes during the focus group discussions, which were audio-recorded and later transcribed verbatim.

We followed an inductive qualitative framework approach ${ }^{44}$ where data analysis informs theory. Consistent with a framework approach, reading the focus group transcripts allowed the members of the research team to familiarize themselves with the data. Next, the team identified key issues, themes and concepts by which the data could be further examined. The team identified five broad themes to examine: current practices, rationalizations, barriers, opportunities and graphic label recommendations. Data excerpts that fit with the identified themes were indexed in the transcripts and then rearranged into thematic charts (a few exemplar excerpts are included in this paper). Finally, the thematic charts were examined with the goal of finding associations and explanations for the findings; a process referred to by Bryman and Burgess ${ }^{44}$ as 'mapping and interpretation'. Analysis of the first four themes is reported elsewhere ${ }^{42-43}$; theme five, 'graphic label recommendations', is reported herein.

\section{Results \& Discussion}

Canadian Smokers' Knowledge of Smoking Causing Blindness

Table 2 summarizes the provincial knowledge data among sampled smokers from Canada in the ITC Four Country phone survey between 2004 and 2008. The proportion of Canadian smokers that knew smoking can cause blindness was notably lower $(14.2 \%)$ than those who discounted the link (69.6\%). Knowledge of this association among Quebec respondents $(20.5 \%)$ was significantly higher than the rest of Canada ( $\mathrm{z}$-score value $6.878, \mathrm{p}<0.0001)$. Only two other provinces, Newfoundland 
TABLE 3

Preferred Graphic Warning Labels Per Category

\begin{tabular}{|c|c|}
\hline Label Category & Preferred Label Content \\
\hline \multicolumn{2}{|c|}{$\begin{array}{l}\text { Eye Disease Graphics } \\
\text { (4 choices) }\end{array}$} \\
\hline \multicolumn{2}{|c|}{$\begin{array}{l}\text { Vision Impact Graphics } \\
\text { (3 choices) }\end{array}$} \\
\hline $\begin{array}{l}\text { Text Information } \\
\text { (3 choices) }\end{array}$ & $\begin{array}{l}\text { WARNING - SMOKING CAUSES BLINDNESS } \\
\text { Smoking is a major cause of blindness. Smoking at least doubles your risk of losing } \\
\text { your sight. When you stop smoking, the risk decreases over time }\end{array}$ \\
\hline
\end{tabular}

and Labrador, and New Brunswick, showed knowledge slightly above the national average. Health Canada's website (www.hc-sc.gc.ca) provides an 'Inventory of Canadian Tobacco Cessation Programs and Resources' provided in each province and territory; in each jurisdiction there is a variety of tobacco prevention and cessation programs yet none of these include any information or explicit content on eye diseases caused by smoking. At this point, we are unsure why knowledge of the link between smoking and vision loss is higher in Quebec than any other province. Yet, even if we focus on the province with the highest knowledge, we are left with the reality that only 1 in 5 smokers know about the link between smoking and blindness. More likely, 1 in 7, at best, know this information. Thus, Canadian optometrists can have an important role in improving patient education about the link between smoking and eye disease. These Canadian findings are comparable with measures of American and UK smoker's knowledge; however, less than that in Australia where social marketing has included the eye and nearly half of smokers were aware of the link. ${ }^{45}$

\section{Perceptions of Eye-Related Graphic Warning Labels}

Analysis of the focus group discussions regarding the graphic warning labels revealed two sub-themes: 1) Accurately Linking Smoking and Blindness, and 2) Framing Desirable Messages. Respondents thought that both the views of optometrists and the public should be considered ultimately in designing a suitable eye-focused graphic warning label.

Both the optometrists and senior optometry students placed high importance on graphic warning labels that accurately linked smoking and blindness. Respondents felt that these labels should 
Endocrine and Metabolism

Glucocorticoids, mostly when systemic exposure occurs, decrease the hypoglycemic activity of insulin and oral hypoglycemics, so that a change in dose of the antidiabetic drugs may be necessitated. In high doses, glucocorticoids also decrease the response to somatotropin. The usual doses of mineralocorticoids and large doses of some glucocorticoids cause hypokalemia and may exaggerate the hypokalemic effects of thiazides and high-ceiling diuretics. In combination with amphotericin-B, they also may cause hypokalemia. Glucocorticoids appear to enhance the ulcerogenic effects of non-steroidal anti-inflammatory drugs. They decrease the plasma levels of salicylates, and salicylism may occur on discontinuing steroids. Glucocorticoids may increase or decrease the effects of prothrombopenic anticoagulants. Estrogens, phenobarbital, phenytoin and rifampin increase the metabolic clearance of adrenal steroids and hence necessitate dose adjustments.

However, given the very low systemic exposure to loteprednol etabonate when using Alrex ${ }^{\infty}$ as directed, these possible effects are not likely.

\section{Immune}

Cortisol and the synthetic analogs of cortisol have the capacity to prevent or suppress the development of the local heat, redness, swelling, and tenderness by which inflammation is recognized. At the microscopic level, they inhibit not only the early phenomena of the inflammatory process (edema, fibrin deposition, capillary dilation, migration of leukocytes into the inflamed area, and phagocytic activity) but also the later manifestations, such as capillary proliferation, fibroblast proliferation, deposition of collagen, and, still later, cicatrisation. Clinical Trial Adverse Drug Reactions Possibly or probably related adverse events from two Phase III studies are listed below:

\begin{tabular}{|c|c|c|}
\hline & $\begin{array}{c}\text { Alrex }^{\circledast 0} 0.2 \% \\
\mathrm{~N}=133\end{array}$ & $\begin{array}{l}\text { Placebo } \\
\mathrm{N}=135\end{array}$ \\
\hline \multicolumn{3}{|l|}{ SPECIAL SENSES (EYE DISORDERS) } \\
\hline \multicolumn{3}{|l|}{ Intraocular Pressure } \\
\hline - elevation of 6 to $9 \mathrm{~mm} \mathrm{Hg}$ & $2 \%$ to $12 \% *$ & $0 \%$ to $6 \%$ \\
\hline - elevation of $\geq 10 \mathrm{~mm} \mathrm{Hg}$ & $1(1 \%)$ & $1(1 \%)$ \\
\hline Chemosis & $6(5 \%)$ & $7(5 \%)$ \\
\hline Vision, Abnormal or Blurred & $4(3 \%)$ & $5(4 \%)$ \\
\hline Burning/stinging, on instillation & $3(2 \%)$ & $6(4 \%)$ \\
\hline Itching Eye & $3(2 \%)$ & $3(2 \%)$ \\
\hline Dry Eye & $2(2 \%)$ & $4(3 \%)$ \\
\hline Burning/stinging, not on instillation & $2(2 \%)$ & $2(1 \%)$ \\
\hline Epiphora & $1(1 \%)$ & $9(7 \%)$ \\
\hline Discharge & $1(1 \%)$ & $3(2 \%)$ \\
\hline Foreign Body Sensation & $1(1 \%)$ & $1(1 \%)$ \\
\hline Discomfort Eye & $1(1 \%)$ & $0(0 \%)$ \\
\hline Injection & $1(1 \%)$ & $0(0 \%)$ \\
\hline Eye Pain & $1(1 \%)$ & $0(0 \%)$ \\
\hline Sticky Eye & $0(0 \%)$ & $7(5 \%)$ \\
\hline Erythema Eyelids & $0(0 \%)$ & $2(1 \%)$ \\
\hline Eye Disorder & $0(0 \%)$ & $2(1 \%)$ \\
\hline \multicolumn{3}{|l|}{ BODY AS A WHOLE } \\
\hline Face Edema (Head) & $1(1 \%)$ & $0(0 \%)$ \\
\hline Allergic Reaction & $1(1 \%)$ & $0(0 \%)$ \\
\hline \multicolumn{3}{|l|}{ MUSCULOSKELETAL SYSTEM } \\
\hline Twitching & $0(0 \%)$ & $1(1 \%)$ \\
\hline
\end{tabular}

One patient in the Alrex ${ }^{\boxplus}$ group and one patient in the placebo group experienced increases in IOP of $\geq 10 \mathrm{~mm} \mathrm{Hg}$. Among these, one in each group had an IOP increase of $\geq 15 \mathrm{~mm} \mathrm{Hg}$, reaching IOP values over $30 \mathrm{~mm} \mathrm{Hg}$. In both studies, there were more patients with IOP increases of 6 to $9 \mathrm{~mm} \mathrm{Hg}$ in the Alrex group than in the placebo group (see table below). In study A, among the patients with IOP increases of 6 to $9 \mathrm{~mm} \mathrm{Hg}$, four reached an IOP value of 22 to $23 \mathrm{~mm} \mathrm{Hg}$, and one patient reached $29 \mathrm{~mm} \mathrm{Hg}$ and was discontinued (clinically significant increase in IOP). All these five patients were from the Alrex ${ }^{\circledast}$ groups.

Incidence of IOP increases of 6 to $9 \mathrm{~mm}$ Hg from baseline (number of patients and percentages)

\begin{tabular}{|cccc|}
\hline & Day 7 & $\begin{array}{c}\text { Duration of treatment } \\
\text { Day 14 }\end{array}$ & Day 28 \\
\hline $\begin{array}{c}\text { Alrex } \\
\text { Study-A } \\
\text { Study-B }\end{array}$ & $\begin{array}{l}6(9 \%) \\
3(5 \%)\end{array}$ & $\begin{array}{l}6(9 \%) \\
1(2 \%)\end{array}$ & $\begin{array}{c}8(12 \%) \\
4(6 \%)\end{array}$ \\
\hline $\begin{array}{c}\text { Placebo } \\
\text { Study-A }\end{array}$ & $0(0 \%)$ & $\begin{array}{l}4(6 \%) \\
0(\%)\end{array}$ & $\begin{array}{c}1(2 \%) \\
0(\%)\end{array}$ \\
\hline Study-B & $0(\%)$ & $\begin{array}{c}0(\%) \\
(0)\end{array}$ & \\
\hline
\end{tabular}

Due to the sample size for each arm of the two phase III studies in SAC, all events captured are greater than $1 \%$ of $n$.

\section{SYMPTOMS AND TREATMENT OF OVERDOSAGE}

For management of suspected accidental oral ingestion or drug overdose, consult your regional poison control centre. No cases of overdose have been reported.

Full Product Monograph available for health professionals at: http://www.bausch.ca

(c) 2008 Bausch \& Lomb Canada Incorporated.

Vaughan Ontario

L4K $4 \mathrm{~B} 4$

IM / depict either common eye diseases associated with smoking (e.g., age-related macular degeneration or cataract) or communicate the experience of vision loss expected from these diseases (e.g., the impact of central vision loss with ARMD). Table 3 shows the most preferred graphic warning label features in the categories of 'Eye Disease', 'Vision Impact' and 'Text Information'. It was very important to respondents that the graphic image be a plausible risk of smoking; for example, respondents objected to one 'Eye Disease Graphic' that appeared more illustrative of eye trauma than smoking. Optometrist O1-1, highlighted this concern, saying, "I think a lot of people smoking are going to go, 'Yeah, right, like that's going to happen to my eye if I smoke! Like give me a break!"”.

Numerous respondents voiced a concern that a majority of the public do not know enough about eyes, eye disease and the links to smoking; thus the graphic label must seem a plausible consequence of smoking despite most viewers having a limited knowledge of the eye and eye disease. The respondents felt that most people could recognize an obviously diseased lung or heart but few would recognize a photo of age-related macular degeneration or cataract. As O1-4 noted after looking at the four 'Eye Disease Graphics', 'You know when a lay person looks at these pictures, half of the time they won't recognize them". In part, because of this lack of knowledge, more of the respondents preferred graphic warning labels that 
showed smoking-induced impacts on vision rather than the related ocular pathology. As one optometry student noted looking at the preferred 'Vision Impact Graphic' (Table 2), "You're putting yourself in those eyes and saying, 'Oh, my God, I won't be able to see my loved ones'. And that hits home" (S3-4). Respondents also preferred text that included direct language, stats and incentives about reducing risk. As S3-2 argued, "I think if you want people to stop smoking you should provide them with the facts."

Respondents also placed a high priority on framing desirable messages. Interestingly, the optometrists and optometry students believed that graphic warning labels are largely intended to motivate quitting through scare tactics but they would rather motivate quitting through education and empowerment. For example, it should be important to those who smoke to know how much their risk of blindness is lowered by tobacco cessation. Numerous respondents indicated that different strategies were needed for youth (e.g., unable to drive a car) than seniors (e.g., unable to see grandchildren). Several respondents also felt that eye diseases seen predominantly in seniors (e.g., AMD, cataract) would not motivate youth to avoid or quit smoking and if there was an age cohort where scare tactics might be successful, it was the youth. As O2-4 noted, "Your older group would appreciate macular degeneration but not if you're targeting the young ones... So, I think you need to have multiple messages".
While optometrists may not have specific training in social judgment, message framing, and statistical heuristics deployed by health psychologists and public health experts, these focus group data show that optometrists have important ideas to contribute to this discussion. Many of the informants in this study supported the idea of having posters and other promotional materials in their practices, provided they judged the materials to be accurate, sensitive and suitable. Thus, if the tobacco control community begins to use eye health related messaging, it will be important to develop messages with which eye care professionals feel comfortable.

\section{Implications}

Consistent with studies of other countries, knowledge is low among Canadian smokers about the causal association of smoking and blindness. Further research is needed to identify the reasons for this limited knowledge; however, with, on average, only 1 in 7 Canadian smokers knowing about this link, there is a clear opportunity for increased patient education by optometrists, other healthcare practitioners and public health workers. Knowing both about the age at which smoking often starts ${ }^{46}$ and its addictive qualities, optometrists should be routinely incorporating interview questions about smoking, starting with patients over 10 years of age. Tobacco use assessment should include the onset, the amount (e.g., number of cigarettes per day) and the type of tobacco use (e.g., smoking, chew, snuff), the interest in quitting and past quit attempts. Tobacco dependence intervention by optometrists can help reduce the health consequences incurred with tobacco use. Toward this end, optometrists can contact their local public health department to learn more about tobacco cessation programs in their area and incorporate some of this information into their patient counseling, including contacts for the national and provincial quit lines. ${ }^{2}$ Like other healthcare providers, optometrists can facilitate higher quit rates among smokers who learn about its health effects and cessation strategies. The 29 optometry participants in this study were clear in their conviction that optometrists should be at the table, helping to design effective educational tools linking smoking to blindness. The findings of this preliminary study may help inform the development of tobacco prevention and cessation tools and materials ultimately used by optometrists in their practices. Optometrists seem to want more of their patients to see the causal association of smoking and blindness, the ocular and systemic benefits of tobacco cessation, and informative, motivating eye health messages about tobacco use.

\section{Acknowledgements}

This study was funded by grants from: 1) CAN-ADAPT'T (Canadian Action Network for Advancement, Dissemination \& Adoption of Practice-informed Tobacco Treatment) through the Tobacco Programs Division, Health Canada, 2) the Ontario Tobacco Research Unit (an Ashley Studentship for 
Research in Tobacco Control), and 3) the Interdisciplinary Capacity Enhancement PanCanadian Resource Network for Tobacco Control, Policy and Practice (ICE-PRN) Learning Opportunities Program (LOP). Violet Zawada (BSc, BEd, MEd), Katy McEwen (BES) and Carla M. Parkinson (BSc, MSW) were research assistants

\section{Footnote}

i The 2008 Canadian study found tobacco users included those who used cigars $(2.6 \%)$, chewing tobacco and snuff $(0.5 \%)$, and pipes $(0.4 \%)$.

ii The national Smoker's Helpline can be contacted via its web-site (http:/ / www.smokershelpline.ca) or phone line (1-877-513-5333). Provincial quit lines are listed on the Health Canada website (http://www.hc-sc.gc.ca), following the links: Home > Health Concerns > Tobacco $>$ Quit Smoking $>$ Quit Now $>$ 1-800 Quit Lines).

\section{References}

1. Reid JL, Hammond D. Tobacco Use in Canada: Patterns and trends, 2009 Edition (v2). Waterloo, Ontario: Propel Centre for Population Health Impact, University of Waterloo, 2009. Accessed April 18, 2010. Available at: http:// www.propel.uwaterloo.ca/_global/ documents/tobacco_use_in_canada_ finalreport_20091030.pdf.

2. McNabola A, Gill LW. The control of environmental tobacco smoke: A policy review, Int J Environ Res Pub Health 2009;6:741-58.

3. Bidwell G, Sahu A, Edwards R, Harrison RA, Thornton J, Kelly SP. Perceptions of blindness related to smoking: a hospital-based crosssectional study. Eye 2005;19:945-8.

4. Ng DHL, Roxburgh STD, Sanjay S, Au Eong KG. Awareness of smoking risks and attitudes towards graphic health warning labels on cigarette packs: a cross-cultural study of two populations in Singapore and Scotland. Eye 2010;24:864-8.

5. Siahpush M, McHeill A, Hammond D, Fong GT. Socioeconomic and country variations in knowledge of health risks of tobacco smoking and toxic constituents of smoke: Results from the 2002 International Tobacco Control (ITC) Four Country Survey. Tob Control 2006;15:iii65-70.

6. Moradi P, Thornton J, Edwards R, Harrison RA, Washington S, Kelly SP. Teenagers' perceptions of blindness related to smoking: a novel message to a vulnerable group. Br J Ophthalmol 2007;91:605-7.

7. Noertjojo K, Maberley D, Bassett K, Courtright P. Awareness of eye diseases and risk factors: Identifying needs for health education and promotion in Canada. Can J Ophthalmol 2006;41:617-23.

8. Solberg Y, Rosner M, Belkin M. The association between cigarette smoking and ocular diseases. Surv Ophthalmol 1998;42:535-47.

9. Khan JC, Thurlby DA, Shahid H, Clayton DG, Yates JRW, Bradley M, Moore AT, Bird AC. Smoking and age related macular degeneration: the number of pack years of cigarette smoking is a major determinant of risk for both geographic atrophy and choroidal neovascularisation. $\mathrm{Br} \mathrm{J}$ Ophthalmol 2006;90:75-80.

10. Neuner B, Wellmann J, Dasch B, Behrens T, Claes B, Dietzel M, Pauleikhoff D, Hense HW. Modeling smoking history: A comparison of different approaches in the MARS Study on age-related maculopathy. Ann Epidem 2007;17:615-21.

11. Smith,W, Mitchell P, Leeder SR. Smoking and age-related maculopathy: The Blue Mountains eye study. Arch Ophthalmol 1996;114:1518-23.

12. Thornton J, Edwards R, Mitchell P, Harrison RA, Buchan I, Kelly SP. Smoking and age-related macular degeneration: A review of association. Eye 2005;19:935-44.
13. Tomany SC, Wang JJ, Van Leeuwen R, Klein R, Mitchell P, Vingerling JR, Klein BEK, Smith W, de Jong PTVM. Risk factors for incident age-related macular degeneration: Pooled findings from 3 continents. Ophthalmol 2004;111:1280-7.

14. Christen WG, Glynn RJ, Ajani UA, Schaumberg DA, Buring JE, Hennekens CH, Manson JE. Smoking cessation and risk of age-related cataract in men. J Am Med Assoc 2000;284:713-6.

15. Cumming RG, Mitchell P. Alcohol, smoking, and cataracts: The Blue Mountains eye study. Arch Ophthalmol 1997;115(10):1296-303.

16. Kelly SP, Thornton J, Edwards R, Sahu A, Harrison RA. The causal association between tobacco smoking and cataract. J Cataract Refract Surg 2005;31:2395404.

17. Krishnaiah S, Vilas K, Shamanna BR, Rao GN, Thomas R, Balasubramanian D. Smoking and its association with cataract: Results of the Andhra Pradesh eye disease study from India. Invest Ophthalmol 2005;46:58-65.

18. McCarty CA, Nanjan MB, Taylor HR. Attributable risk estimates for cataract to prioritize medical and public health action. Invest Ophthal Vis Sci 2000;41:3720-5.

19. Weintraub JM, Willett WC, Rosner B, Colditz GA, Seddon JM, Hankinson SE. Smoking cessation and risk of cataract extraction among US women and men. Am J Epidem 2002;155:72-9.

20. Cawood TJ, Moriarty P, O'Farrelly C, O'Shea D. Smoking and thyroidassociated ophthalmopathy: A novel explanation of the biological link. J Clin Endocrin Metab 2007;92:59-64.

21. Hegedus L, Brix T, Vestergaard P. Relationship between cigarette smoking and Graves' ophthalmopathy. J Endocrin Invest 2004;27:265-71.

22. Thornton J, Kelly SP, Harrison RA, Edwards R. Cigarette smoking and thyroid eye disease: a systematic review. Eye 2007;21:1135-45. 
23. Chung SM, Gay CA, McCrary JA. Nonarteritic ischemic optic neuropathy. The impact of tobacco use. Ophthalmol 1994;101:781-3.

24. Rizzo JF, Lessell S. Tobacco amblyopia. Am J Ophthalmol 1993;116:84-7.

25. Sadun F, De Negri AM, Carelli V, Salomao SR, Berezovsky A, Andrade R, Moraes M, Passos A, Belfort R, DaRosa AB, Quiros P, Sadun AA. Ophthalmologic findings in a large pedigree of 11778/Haplogroup J Leber hereditary optic neuropathy. Am J Ophthalmol 2004;137:271-7.

26. Lin P, Loh AR, Margolis TP, Acharya NR. Cigarette smoking as a risk factor for uveitis. Ophthalmol 2010;117:58590.

27. Thorne JE, Daniel E, Jabs DA. Kedhar SR, Peters GB, Dunn JP. Smoking as a risk factor for cystoid macular edema complicating intermediate uveitis. Am J Ophthalmol 2008;145:841-6.

28. Thornton J, Torun P, Edwards R, Harrison A, Kelly SP, Harrison RA, Verma A. Pharmacists could include this information in their advice to clients who smoke, as an additional means to promote smoking cessation. Inter J Pharm Practice 2008;6:251-6.

29. An LC, Foldes SS, Alesci NL, Bluhm JH, Bland PC, Davern ME, Schillo BA, Ahluwalia JS, Manley MW. The impact of smoking-cessation intervention by multiple health professionals. Am J Prevent Med 2008;34:54-60.

30. Carr AB, Ebbert JO. Interventions for tobacco cessation in the dental setting. A systematic review. Commun Dent Health 2007;24(2):70-4.

31. Centers for Disease Control and Prevention (CDC). Smoking-cessation advice from health-care providers-Canada, 2005. Morbid Mortal Weekly Report 2007;56:708-12.

32. Conroy MB, Majchrzak NE, Regan S, Silverman CB, Schneider LI, Rigotti NA. The association between patient-reported receipt of tobacco intervention at a primary care visit and smokers' satisfaction with their health care. Nicotine Tob Res 2005;7(Suppl 1):S29-34.
33. McIntosh S, Ossip-Klein DJ, Spada J, Burton K. (2000). Recruitment strategies and success in a multi-county smoking cessation study. Nicotine Tob Res 2000;2(3):281-4.

34. Stead LF, Bergson G, Lancaster T. Physician advice for smoking cessation. Cochrane Database System Rev (Online) 2008;(2)(2):CD000165.

35. US Surgeon General. Treating Tobacco Use and Dependence: 2008 Update. Cited December 13, 2009. Available at http://www.surgeongeneral.gov/ tobacco/.

36. Hammond D, Fong GT, McNeill A, Borland R, Cummings KM. Effectiveness of cigarette warning labels in informing smokers about the risks of smoking: Findings from the International Tobacco Control (ITC) Four Country Survey, Tob Control 2006;15:iii19-25.

37. Carroll T, Rock B. Generating quitline calls during Australia's National Tobacco Campaign: Effects of television advertisement execution and programme placement. Tob Control, 2003;12:ii40-4.

38. Wilson N, Grigg M, Cameron G, Afzal R, Glasgow H. Smoking and blindness advertisements are effective in stimulating calls to a national quitline. Letter to the Editor. Br Med J 2004;238:537-8.

39. Fong GT, Cummings KM, Borland R, Hastings G, Hyland A, Giovino GA, et al. The conceptual framework of the International Tobacco Control (ITC) Policy Evaluation Project, Tob, Control 2006;15:iii3-11.

40. Thompson ME, Fong GT, Hammond D, Boudrea C, Driezen P, Hyland A, et al. Methods of the International tobacco Control (ITC) Four Country Survey. Tob Control 2006;15:iii12-18.

41. ITC Four Country Survey Team. International Tobacco Control Policy Evaluation Survey (ITC 4-Country Survey Wave 1 Technical Report. http://www.itcproject.org/Library/ countries/4country/reports/ itcw1 techr. (Accessed November 7, 2010).
42. Spafford MM, Iley MD, Schultz ASH, \& Kennedy RD. Tobacco dependence education in optometry: A Canadian pilot study assessing practices and opportunities. Optom Educ 2010;36:38-44.

43. Kennedy RD, Spafford MM, Schultz ASH, Iley MD, Zawada V. Smoking cessation referrals in optometric practice: A Canadian pilot study. Optom Vis Sci Accepted December 2010.

44. Bryman A, Burgess R. editors. Analysing qualitative data. London: Routledge, 1993.

45. Kennedy RD, Spafford MM, Parkinson CM, Fong GT. Knowledge about the relationship between smoking and blindness in Canada, United States, United Kingdom and Australia: Results from the ITC Four Country Survey. Optometry, Accepted December 2010.

46. American Medical Association. Guidelines for adolescent preventive health services. Chicago: American Medical Association, 1993.

Table 1: Graphic Warning Label Features Discussed

\section{Authors}

Marlee M. Spafford, OD, PhD

University of Waterloo, School of Optometry

Ryan D. Kennedy, MAES, PhD University of Waterloo, Propel Centre for Population Health Impact

Matthew D. Iley, BSc, OD

University of Waterloo, School of

Optometry

Annette S.H. Schultr, RN, PhD University of Manitoba, Faculty of Nursing 